\title{
Adição de polieletrólito ao processo de floculação no pós-tratamento de lixiviado por coagulação-floculação-sedimentação
}

\section{Addition to polyelectrolyte flocculation process in post leachate treatment coagulation-sedimentation-flocculation}

\author{
Anelise Passerine de Castro \\ Engenheira Ambiental. Mestranda em Engenharia de Edificações e Saneamento pela Universidade Estadual de Londrina (UEL) - Londrina (PR), Brasil
}

Fábio Yamashita

Engenheiro de Alimentos. Doutor em Engenharia de Alimentos. Professor Associado da UEL - Londrina (PR), Brasil

\section{Sandra Márcia Cesário Pereira da Silva}

Engenheira Civil. Doutora em Engenharia Civil. Professora Associada da UEL - Londrina (PR), Brasil

\section{Resumo}

A adição de polieletrólito ao processo de floculação no tratamento físico-químico por coagulação-floculação-sedimentação de efluentes tem sido uma alternativa para a obtenção de clarificados de boa qualidade em menor tempo devido ao aumento da velocidade de sedimentação. Deste modo, este artigo, objetivou determinar as inter-relações entre as variáveis pH, gradiente de floculação, dosagem de ferro e tipo de polieletrólito e avaliar o efeito desta adição na remoção de cor, DQO e turbidez no pós-tratamento do lixiviado submetido a tratamento biológico. Através do uso da técnica de planejamento e analisando-se os resultados obtidos, pôde-se verificar que o polímero de carga catiônica apresentou-se como o mais eficiente, obtendo remoções de até 97,70\% para cor verdadeira, $81,52 \%$ para DQO e $92,18 \%$ para turbidez.

Palavras-chave: lixiviado; polieletrólito; velocidade de sedimentação.

\section{Abstract}

The addition of polyelectrolyte flocculation process in the physical-chemical treatment by coagulation-flocculation-sedimentation effluent has been an alternative to obtain clarification of good quality in less time due to increased sedimentation rate. Thus, this article aimed to determine the interrelationships between the pH gradient, flocculation, iron dosage and type of polyelectrolyte and evaluate the effect of this addition on color removal, COD and turbidity in the post-treatment of the leachate subjected to pretreatment biological. Through the use of technical planning and analyzing the results, it was found that the polymer cationic charge introduced himself as the most efficient, achieving removals of up to $97.70 \%$ for true color, $81.52 \%$ for COD and $92.18 \%$ for turbidity.

Keywords: leachate; polyelectrolyte; sedimentation rate.

\section{Introdução}

O lixiviado encontrado em aterros de resíduos sólidos urbanos é um líquido resultante da interação entre o processo de biodegradação da fração orgânica de resíduos e da infiltração de águas pluviais que solubilizam componentes orgânicos, que apresenta cor escura e alto potencial de contaminação do solo e das águas superficiais e subterrâneas. Além disso, apresenta composição variada dependendo da idade do aterro sanitário, do grau de estabilização e características do material sólido aterrado e do regime de chuvas. Em geral, apresenta como características altas concentrações de $\mathrm{N}$-amoniacal, matéria orgânica e compostos orgânicos de difícil degradação, como as substâncias húmicas e fúlvicas (WISZNIOWSKI et al., 2006; KJELDSEN et al., 2002), requerendo, portanto, tratamentos específicos que reduzam sua carga tóxica e poluidora. 
Embora os métodos de tratamento atualmente mais utilizados empreguem o processo biológico, diversos estudos têm demonstrado que em lixiviados de aterros com mais de 10 anos, já estabilizados e que apresentam uma maior quantidade de compostos recalcitrantes, o tratamento biológico é pouco eficiente (TATSI et al., 2003; ZOUBOULIS; CHAI; KATSOYIANNIS, 2004; WISZNIOWSKI et al., 2006). Por isso, essa forma de tratamento deve sempre vir acompanhada de outras tecnologias de tratamento (KURNIAWAN; LO; CHANG, 2005).

Nesse contexto, o pós-tratamento físico-químico através do processo de coagulação-floculação-sedimentação pode ser uma alternativa para a remoção de compostos indesejáveis, como os recalcitrantes e os de difícil biodegradação, que não foram removidos pelo tratamento de natureza biológica, visando principalmente a remoção de demanda química de oxigênio (DQO) e cor a níveis satisfatórios para, posteriormente, ser lançado no ambiente.

Em estudos já realizados por Maringonda Junior (2008), observou-se que o lixiviado proveniente do aterro controlado de resíduos sólidos urbanos de Londrina apresenta fração orgânica de difícil biodegradação, com características de fase metanogênica. Segundo Kulikowska e Klimiuk (2008), esta fase apresenta alto teor de substâncias húmicas, as quais conferem características recalcitrantes ao lixiviado. Essas substâncias são geralmente de coloração escura, elevada massa molecular, estrutura química complexa e indefinida, resultantes da decomposição de vegetais e animais (ROCHA; ROSA, 2003), sendo as principais responsáveis pela conferência de cor no lixiviado.

Posteriormente, Felici (2010), utilizando lixiviado proveniente do mesmo aterro, verificou que o uso combinado do processo biológico de lodo ativado em batelada e físico-químico por coagulação-floculação-sedimentação apresentou remoções de 98 e 80,9\%, respectivamente, para as variáveis cor verdadeira e DQO no tratamento. Entretanto, a velocidade de sedimentação encontrada não se mostrou aplicável à escala real, sendo necessário obter uma alternativa para aumentar a velocidade e consequentemente reduzir o tempo de sedimentação.

Em efluente oriundo das etapas de acabamento molhado do couro, Hoffman (2007) observou que a adição do polieletrólito teve uma influência positiva na obtenção de um clarificado de boa qualidade em menor tempo, quando comparada ao tratamento em que foi adicionado somente o coagulante.

Deste modo, os objetivos deste artigo foram selecionar o tipo de polieletrólito que, adicionado na etapa de floculação do processo físico-químico utilizado como pós-tratamento do lixiviado submetido a tratamento biológico, resulte em maiores eficiências de remoção de cor verdadeira, DQO e turbidez, bem como determinar suas inter-relações com as variáveis $\mathrm{pH}$, gradiente de floculação e dosagem de ferro.

\section{Método}

O trabalho foi dividido em etapas: i) Caracterização do lixiviado; ii) Planejamento experimental; iii) Tratamento físico-químico por coagulação-floculação-sedimentação com adição de polieletrólitos catiônico, aniônico e não iônico na etapa de floculação; iv) Interpretação dos resultados analíticos resultantes do desenvolvimento experimental.

Tabela 1 - Parâmetros investigados e metodologia utilizada na caracterização do lixiviado.

\begin{tabular}{|c|c|}
\hline Parâmetro & Método \\
\hline $\mathrm{pH}$ & Método potenciométrico ${ }^{1}$ \\
\hline Temperatura & 2550 B - Termômetro de Mercúrio ${ }^{1}$ \\
\hline Cor verdadeira $(\mathrm{uH})$ & Método espectrofotométrico - 405 nm \\
\hline Cor aparente $(\mathrm{uH})$ & Método espectrofotométrico - $405 \mathrm{~nm}$ \\
\hline Turbidez (UT) & $2130 \mathrm{~B}$ - Método nefelométrico ${ }^{1}$ \\
\hline DBO & $5210 \mathrm{~B}$ - Teste DBO 5 dias a $20^{\circ} \mathrm{C}^{1}$ \\
\hline DQO & 5220 C - Método do refluxo fechado ${ }^{1}$ \\
\hline $\mathrm{N}$-amoniacal & 4500- $\mathrm{NH}_{3} \mathrm{~B}$ e C - Destilação e titulação ${ }^{1}$ \\
\hline NKT & 4500-Norg B e C - Micro-Kjeldhal ${ }^{1}$ \\
\hline Nitrito & 4500- $\mathrm{NO}_{2}^{-} \mathrm{B}$ - Método colorimétrico ${ }^{1}$ \\
\hline Nitrato & Método do ácido salicílico² \\
\hline Sólidos totais & $2540 \mathrm{~B}$ - Sólidos totais secos a $103-105^{\circ} \mathrm{C}^{1}$ \\
\hline Sólidos em suspensão & $2540 \mathrm{E}$ - Sólidos voláteis incinerados a $550^{\circ} \mathrm{C}^{1}$ \\
\hline
\end{tabular}

DBO: demanda biológica de oxigênio; DQO: demanda química de oxigênio; NKT: nitrogênio Kjeldhak total. ${ }^{1}$ Standard Methods (APHA; AWWA; WEF, 2005); ${ }^{2}$ Cataldo et al. (1975).

Tabela 2 - Variáveis e níveis definidos para o planejamento fatorial.

\begin{tabular}{lccc} 
Variáveis & \multicolumn{3}{c}{ Valores codificados } \\
independentes & -1 & $\mathbf{0}$ & $\mathbf{1}$ \\
\hline Dosagem $\mathrm{Fe}^{+3}\left(\mathrm{mg} \mathrm{L}^{-1}\right)$ & 150 & 225 & 300 \\
\hline Polieletrólito $($ Pol.) & Aniônico & Catiônico & Nônico \\
\hline Gradiente de floculação $\left(\mathrm{s}^{-1}\right)($ Gfloc) & 20 & 30 & 40 \\
$\mathrm{pH}$ & 2,5 & 3,5 & 4,5 \\
\hline
\end{tabular}

Pol.: polímero; Gfloc: gradiente de floculação. 


\section{Caracterização do lixiviado}

O lixiviado utilizado provinha de um tratamento biológico por lodo ativado em batelada em escala piloto, precedido de tanques de stripping de amônia. O mesmo foi caracterizado segundo os métodos analíticos, descritos em APHA, AWWA e WEF (2005) e Cataldo et al. (1975), conforme a Tabela 1.

\section{Planejamento experimental}

A técnica de planejamento experimental $3^{4}$ Box Behnken foi empregada visando otimizar o processo de tratamento empregado. Para tanto, utilizaram-se as variáveis independentes e seus respectivos níveis, conforme a Tabela 2.

Baseando-se em valores já utilizados por Bila et al. (2005) e Sarasa et al. (2006), foram utilizadas dosagens de 3,0; 2,0 e 3,0 $\mathrm{mg} \mathrm{L}^{-1}$, respectivamente, para os polieletrólitos de carga catiônica, aniônica e não iônica.

As variáveis respostas observadas foram a porcentagem de remoção de cor verdadeira, DQO filtrada e turbidez.

\section{Tratamento físico-químico por coagulação-floculação- sedimentação com adição de polieletrólitos catiônico, aniônico e não iônico na etapa de floculação}

O processo físico-químico foi realizado em escala de bancada, através de equipamento Jartest modelo 218 LDB (Nova Ética) e, foram utilizados como coagulante cloreto férrico $\left(\mathrm{FeCl}_{3} \cdot 6 \mathrm{H}_{2} \mathrm{O}\right)$, acidificante ácido clorídrico 20\% v/v ( $\mathrm{HCl})$, polieletrólitos Kemira catiônico carga 10\%, aniônico carga 30\% e não iônico carga 0\%.

Para efeitos de comparação com trabalhos anteriormente realizados com o mesmo lixiviado sem adição de polieletrólito, foram empregadas as mesmas condições operacionais utilizadas por Felici (2010) no ensaio de jarteste. Desse modo, fixou-se o tempo de mistura rápida (Tmr) em 60 segundos, o tempo de floculação (Tfloc) em 20 minutos e o gradiente de mistura rápida em $600 \mathrm{~s}^{-1}$.

Para a determinação do tempo de sedimentação, foram realizados testes preliminares para verificar um tempo mínimo que permitisse a sedimentação dos lodos de modo a não interferir na retirada dos sobrenadantes dos jarros. Deste modo, verificou-se que em 30 minutos, o lodo gerado durante o processo já havia se sedimentado. A adoção de tal tempo mostra-se significativamente menor que a adotada por Felici (2010), que empregando lixiviado tratado biologicamente com características semelhantes às deste trabalho, utilizou seis horas de sedimentação para pós-tratamento por coagulação-floculação-sedimentação. Tal diferença deve ser creditada ao uso de polieletrólitos no processo de floculação, já que nos estudos realizados por este autor, não foram utilizados floculantes.

\section{Interpretação dos resultados analíticos resultantes do desenvolvimento experimental}

A análise dos resultados foi realizada através da interpretação das respostas obtidas no planejamento experimental. Após o processamento analítico para determinação da DQO, cor e turbidez das amostras coletadas do sobrenadante do processo de tratamento, os resultados foram processados através do software Statistica, obtendo-se as superfícies de respostas de acordo com a variável selecionada, as equações lineares dos modelos determinados para as faixas das variáveis estabelecidas no estudo e os valores previstos.

\section{Resultados e discussão}

O lixiviado biologicamente tratado, utilizado durante os experimentos, foi caracterizado segundo os parâmetros apresentados na Tabela 3

Analisando-se a Tabela 3, observa-se que o lixiviado proveniente da etapa de tratamento biológico apresenta altas concentrações de matéria orgânica (na forma de DQO) e cor, sendo, portanto, necessária e justificável, uma etapa seguinte de tratamento físico-químico para redução destes parâmetros.

Deste modo, para esta fase posterior, foram utilizados os processos de coagulação-floculação-sedimentação, nos quais, utilizando-se a técnica de planejamento Box Behnken da ordem de $3^{4}$, foi gerado um total de 27 ensaios. Os resultados dos experimentos, agrupados de acordo com o tipo de polieletrólito utilizado, são apresentados na Tabela 4.

Tabela 3 - Caracterização do lixiviado biologicamente tratado por lodo ativado em batelada em escala piloto, precedido de tanques de stripping de amônia.

\begin{tabular}{|c|c|}
\hline Parâmetro & Valores \\
\hline $\mathrm{pH}$ & 9,00 \\
\hline Temperatura $\left({ }^{\circ} \mathrm{C}\right)$ & 25,80 \\
\hline Cor verdadeira $(\mathrm{uH})$ & 5.134 \\
\hline Cor aparente $(\mathrm{uH})$ & 5.811 \\
\hline Turbidez (UT) & 140,00 \\
\hline $\mathrm{DBO}\left(\mathrm{mg} \mathrm{O}_{2} \mathrm{~L}^{-1}\right)$ & 35,00 \\
\hline $\mathrm{DQO}\left(\mathrm{mg} \mathrm{L}^{-1}\right)$ & 2.650 \\
\hline $\mathrm{N}$-amoniacal (mg L-1) & 13,00 \\
\hline NKT (mg L-1) & 104,00 \\
\hline Nitrito $\left(\mathrm{mg} \mathrm{L}^{-1}\right)$ & 1,00 \\
\hline Nitrato (mg L-1) & 11,60 \\
\hline Sólidos totais (mg L-1) & 9.625 \\
\hline Sólidos em suspensão (mg L-1) & 82,00 \\
\hline
\end{tabular}

DBO: demanda biológica de oxigênio; DQO: demanda química de oxigênio; NKT: nitrogênio Kjeldhak total. 
A análise destes resultados possibilitou estabelecer um modelo matemático e encontrar os fatores que interferem no processo e suas inter-relações, considerando a remoção de cor verdadeira, DQO e turbidez, além de indicar o tipo de polieletrólito mais indicado para o tratamento nas faixas e condições operacionais estudadas do lixiviado em questão.

Para o parâmetro cor verdadeira, o modelo matemático ajustado é capaz de explicar aproximadamente $79 \%\left(R^{2}=0,7862\right)$ da variabilidade na porcentagem de remoção de cor verdadeira, sendo apresentado na Equação 1.

$\mathrm{y}($ cor verdadeira $)=86,58+5,20\left(\mathrm{Fe}^{3+}\right)+2,09\left(\mathrm{Fe}^{3+}\right)^{2}-4,35(\mathrm{pol}$.

$+2,55(\mathrm{pol} .)^{2}+2,95(\mathrm{pH})^{2}+9,37\left(\mathrm{Fe}^{3+*}\right.$ pol. $)$

$+4,90\left(\mathrm{Fe}^{3+*} \mathrm{pH}\right)-4,07$ (pol. $\left.{ }^{*} \mathrm{Gfloc}\right)-2,55$ (pol. * pH)

Sendo:

$\mathrm{Fe}^{3+}$ : dosagem de cloreto férrico em $\mathrm{mg} \mathrm{Fe} \mathrm{Fe}^{+3} \mathrm{~L}^{-1}$

pol.: polímero;

Gfloc: gradiente de floculação.

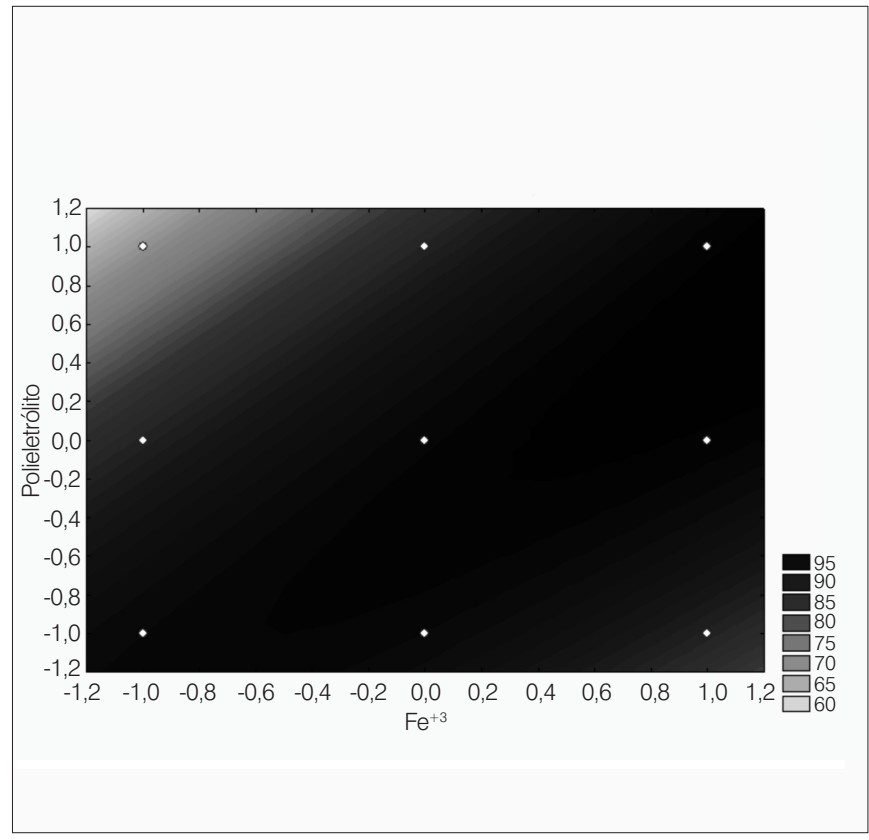

Figura 1 - Superfície de resposta para variável cor verdadeira em função dos valores codificados das variações de $\mathrm{Fe}^{3+}$ e polieletrólito.

Tabela 4 - Resultados dos 27 ensaios do processo de coagulação-floculação-sedimentação do lixiviado biologicamente tratado, utilizando-se cloreto férrico e polieletrólito.

\begin{tabular}{|c|c|c|c|c|c|c|c|}
\hline & \multicolumn{4}{|c|}{ Variáveis independentes } & \multicolumn{3}{|c|}{ Variáveis respostas } \\
\hline & Polieletrólito & $\begin{array}{c}\mathrm{Fe}^{3+} \\
\left(\mathrm{mg} \mathrm{L}^{-1}\right)\end{array}$ & $\begin{array}{c}\text { Gfloc } \\
\left(\mathrm{s}^{-1}\right)\end{array}$ & $\mathrm{pH}$ & $\begin{array}{c}\text { Remoção cor } \\
\text { verdadeira (\%) }\end{array}$ & $\begin{array}{c}\text { Remoção DQO } \\
(\%)\end{array}$ & $\begin{array}{l}\text { Remoção } \\
\text { turbidez (\%) }\end{array}$ \\
\hline 1 & \multirow{15}{*}{ Catiônico } & 225 & 20 & 2,5 & 87,9 & 77,39 & 96,22 \\
\hline 2 & & 225 & 40 & 2,5 & 89,4 & 66,88 & 85,33 \\
\hline 3 & & 225 & 20 & 4,5 & 87,2 & 71,31 & 56,25 \\
\hline 4 & & 225 & 40 & 4,5 & 92,1 & 77,88 & 81,23 \\
\hline 5 & & 225 & 30 & 3,5 & 97,0 & 77,91 & 98,99 \\
\hline 6 & & 150 & 30 & 2,5 & 89,6 & 74,43 & 98,72 \\
\hline 7 & & 300 & 30 & 2,5 & 85,8 & 75,36 & 97,63 \\
\hline 8 & & 150 & 30 & 4,5 & 75,2 & 64,70 & 70,45 \\
\hline 9 & & 300 & 30 & 4,5 & 91,0 & 73,81 & 84,83 \\
\hline 10 & & 225 & 40 & 3,5 & 96,2 & 81,80 & 83,10 \\
\hline 11 & & 150 & 20 & 3,5 & 94,0 & 76,45 & 97,80 \\
\hline 12 & & 300 & 20 & 3,5 & 97,7 & 81,42 & 86,70 \\
\hline 13 & & 150 & 40 & 3,5 & 93,7 & 75,12 & 97,82 \\
\hline 14 & & 300 & 40 & 3,5 & 97,7 & 81,52 & 92,18 \\
\hline 15 & & 225 & 30 & 3,5 & 95,6 & 79,43 & 98,81 \\
\hline 16 & \multirow{6}{*}{ Aniônico } & 150 & 30 & 3,5 & 93,4 & 72,75 & 96,72 \\
\hline 17 & & 300 & 30 & 3,5 & 96,0 & 78,83 & 75,42 \\
\hline 18 & & 225 & 20 & 3,5 & 86,7 & 68,09 & 50,52 \\
\hline 19 & & 225 & 40 & 3,5 & 96,1 & 82,94 & 54,54 \\
\hline 20 & & 225 & 30 & 2,5 & 87,4 & 74,28 & 95,90 \\
\hline 21 & & 225 & 30 & 4,5 & 96,0 & 79,05 & 97,75 \\
\hline 22 & \multirow{6}{*}{ Não iônico } & 225 & 20 & 3,5 & 93,5 & 78,72 & 96,97 \\
\hline 23 & & 225 & 30 & 3,5 & 86,6 & 74,00 & 58,98 \\
\hline 24 & & 225 & 30 & 2,5 & 86,3 & 74,35 & 93,76 \\
\hline 25 & & 225 & 30 & 4,5 & 84,7 & 72,67 & 51,94 \\
\hline 26 & & 150 & 30 & 3,5 & 56,1 & 60,76 & 62,15 \\
\hline 27 & & 300 & 30 & 3,5 & 96,2 & 80,47 & 84,33 \\
\hline
\end{tabular}

Gfloc: gradiente de floculação; DQO: demanda química de oxigênio. 
Analisando-se a equação para tal parâmetro, pode-se verificar que as variáveis dosagem de ferro e polieletrólito apresentaram maiores efeitos principais sobre a eficiência do processo, bem como possuem uma grande inter-relação. Como a adição de polieletrólitos no processo de floculação pode influir na dosagem de coagulante primário, esta inter-relação já era esperada.

Conforme superfície de resposta em função das variáveis $\mathrm{Fe}^{3+} \mathrm{e}$ polieletrólito mostrada na Figura 1, observa-se que as áreas de maior eficiência ocorrem quando a dosagem de coagulante assume valores próximos a $225 \mathrm{mg} \mathrm{Fe} \mathrm{Fe}^{3+} \mathrm{L}^{-1} \mathrm{em}$ conjunto com polieletrólito catiônico ou dosagens de $300 \mathrm{mg} \mathrm{Fe}^{3+} \mathrm{L}^{-1}$ combinado com polieletrólitos não iônico ou catiônico.

Observando-se a Tabela 4, com exceção dos experimentos 8 e 26 , verifica-se que os índices de remoção para cor verdadeira mostraram-se superiores a $84 \%$. Tais resultados mostraram-se superiores aos obtidos por Silva (2002), que em experimentos semelhantes empregando sulfato de alumínio como coagulante, obteve eficiência máxima de 70\%, o que vem reforçar a utilização de sais de ferro no processo de coagulação química em virtude de sua maior eficiência na remoção de poluentes.

Numa análise dos valores previstos (Figura 2), obtidos pelo programa Statistica, verifica-se que as maiores remoções de cor verdadeira ocorrerão quando a dosagem de ferro aproxima-se a $300 \mathrm{mg} \mathrm{Fe}^{+3} \mathrm{~L}^{-1}$ em conjunto com a adição de polieletrólito catiônico e $\mathrm{pH}$ próximo a 3,5. Com relação ao gradiente de floculação, observa-se uma tendência linear, de forma que qualquer valor assumido na faixa testada não ocasione ganhos ou perdas à eficiência de remoção do parâmetro.

Para a variável DQO, determinou-se o modelo apresentado na Equação 2, o qual explica $81 \%\left(R^{2}=0,81347\right)$ da variabilidade na eficiência de remoção do parâmetro.

$y(\mathrm{DQO})=73,32+3,93\left(\mathrm{Fe}^{3+}\right)^{2}+1,20\left(\mathrm{Fe}^{3+}\right)^{2}-1,24$ (pol. $)+1,12$ $(\text { pol. })^{2}$

$+2,05(\mathrm{pH})^{2}+3,40\left(\mathrm{Fe}^{3+*}\right.$ pol. $)+2,04\left(\mathrm{Fe}^{3+*} \mathrm{pH}\right)$

$-4,89$ (pol. * Gfloc) - 1,61 (pol. * pH) + 4,27 (Gfloc * pH)

Através deste modelo, é possível observar que a variável Gfloc não apresenta efeito principal para a remoção de DQO, enquanto dosagem de $\mathrm{Fe}^{3+}$ e pH são as mais representativas sobre o lixiviado utilizado. A influência do pH na eficiência de remoção da DQO pode ser explicada pelo fato da coagulação química ser altamente dependente do parâmetro, bem como agir diretamente sobre a dissolução do metal coagulante.

Assim como no modelo matemático obtido para cor verdadeira, pode-se observar também, na Equação 2, que as variáveis gradiente de floculação e polieletrólito apresentaram correlação. Embora não apontassem a existência dessa correlação, Bila (2000) e Roehrs (2007) ressaltaram os valores do gradiente utilizados durante os experimentos, demonstrando a importância deste parâmetro para a

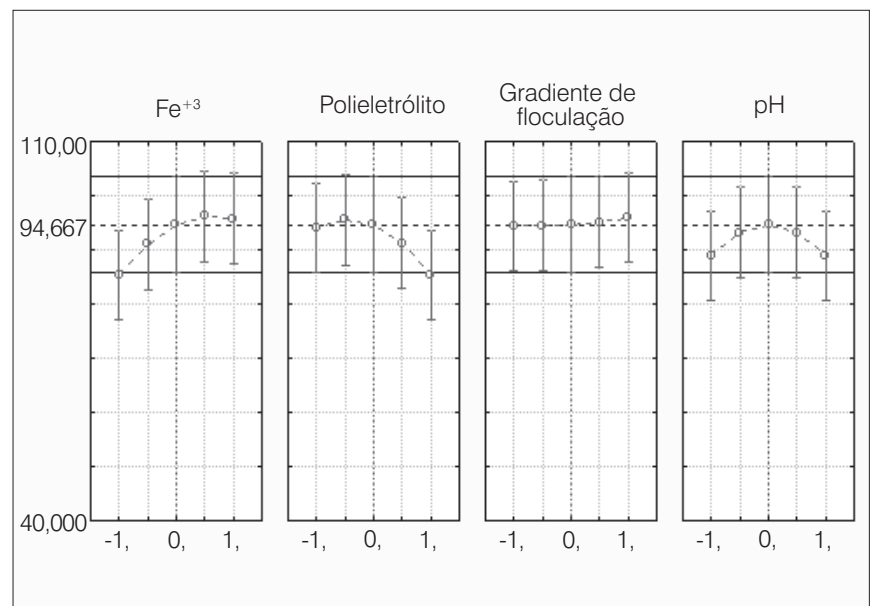

Figura 2 - Valores previstos para o modelo matemático da variável cor verdadeira.

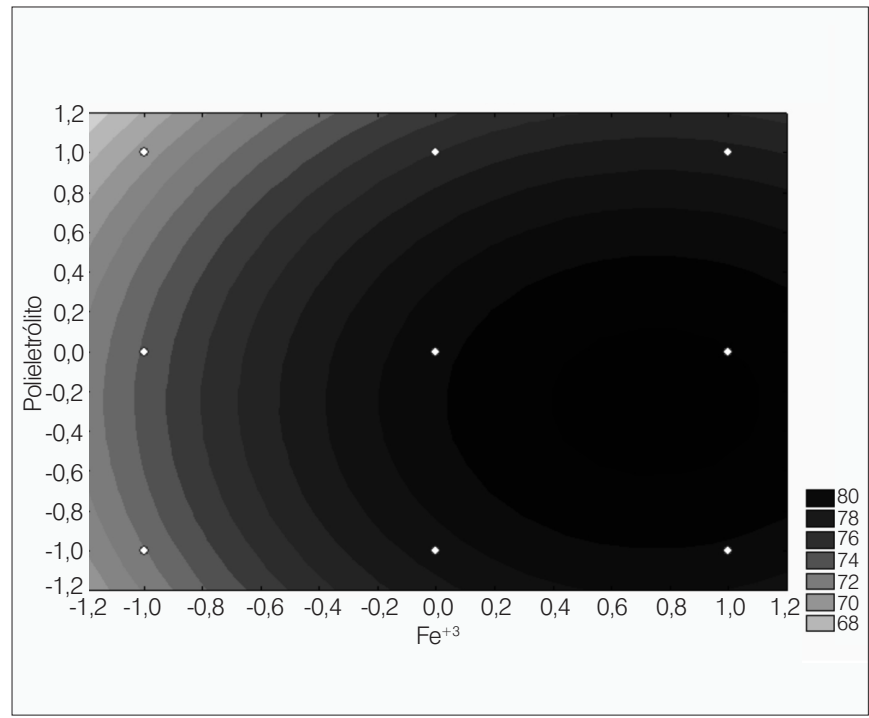

Figura 3 - Superfície de resposta para variável DQO em função das variáveis codificadas de polieletrólito e dosagem de $\mathrm{Fe}^{+3}$ para os ensaios 1 a 27.

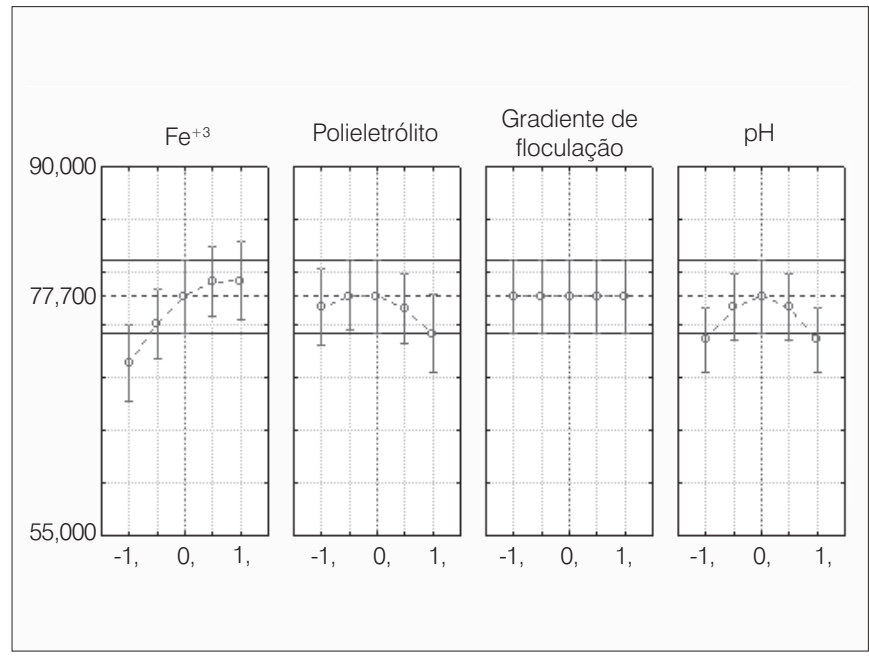

Figura 4 - Valores previstos para o modelo matemático da variável DQO. 
eficácia do processo quando da adição de polieletrólito no processo de floculação.

Observa-se pela Figura 3 que os melhores resultados de remoção de DQO foram com polieletrólito catiônico e dosagem de coagulante próxima a $300 \mathrm{mg} \mathrm{Fe} \mathrm{F}^{+3} \mathrm{~L}^{-1}$.

$\mathrm{Na}$ Figura 4 é possível verificar que as maiores remoções do parâmetro DQO poderão ocorrer quando a dosagem de ferro mantiver-se em $300 \mathrm{mg} \mathrm{Fe}^{+3} \mathrm{~L}^{-1}$, pH igual a 3,5, e polieletrólito catiônico. Novamente, o gradiente de floculação não apresentou interferência no processo.

Estudos semelhantes com o tratamento de lixiviado por coagulação-floculação-sedimentação com adição de polieletrólitos, foram realizados por Amokrane, Comel e Veron (1997) e Bila et al. (2005). Em ambos, as eficiências de remoção de DQO encontradas não foram superiores a 50\%. Ao compararem-se estes resultados aos obtidos no presente estudo, pode-se verificar que as dosagens de coagulante utilizadas, bem como as variações de gradiente de floculação e pH mostraram-se de grande relevância às eficiências obtidas, já que nos experimentos 10, 12, 14 e 19, por exemplo, remoções acima de 81\% foram encontradas.

A Equação 3 apresenta o modelo matemático para a variável remoção de turbidez, o qual explica aproximadamente $74 \%$ $\left(R^{2}=0,74066\right)$ das variações na eficiência de remoção do parâmetro. $y($ turbidez $)=77,04-1,89$ (pol. $)+7,21(\text { pol. })^{2}+4,99(\text { Gfloc })^{2}-10,42(\mathrm{pH})+$ $1,53(\mathrm{pH})^{2}+10,87\left(\mathrm{Fe}^{3+*}\right.$ pol. $)+1,36\left(\mathrm{Fe}^{+3} * \mathrm{Gfloc}\right)+3,86\left(\mathrm{Fe}^{3+*} \mathrm{pH}\right)-$ 10,50 (pol. * Gfloc) - 10,91 (pol. * pH) + 8,96 (Gfloc*pH)

Para a Equação 3, os efeitos principais sobre a remoção de turbidez são polieletrólito e pH. Diferentemente das demais equações encontradas, neste modelo, a dosagem de coagulante não apresentou efeitos principais, indicando não ser esta a variável de maior significância para o processo de tratamento para remoção de turbidez. No entanto, é possível observar uma forte inter-relação entre a dosagem de coagulante e o polieletrólito.

$\mathrm{Na}$ Figura 5, que representa a superfície de resposta obtida em função do polieletrólito e $\mathrm{pH}$, observa-se que o polieletrólito catiônico e pH próximo a 2,5 acarretam maior eficiência à remoção de turbidez.

As maiores remoções de turbidez ocorreram nos experimentos 5, 6 e 15, alcançando índices superiores a 98\%. Em estudos realizados por Marañon et al. (2008), as remoções giraram em torno de $90 \%$.

Através dos valores previstos apresentados na Figura 6, observa-se que o comportamento da variável polieletrólito, visando remoção da turbidez, mostra-se semelhante aos já encontrados para os parâmetros cor verdadeira e DQO.

Em estudos anteriores, ao utilizar o lixiviado tratado biologicamente do aterro controlado de Londrina, Felici (2010) obteve remoções de 98 e 80,9\%, respectivamente, para as variáveis cor verdadeira

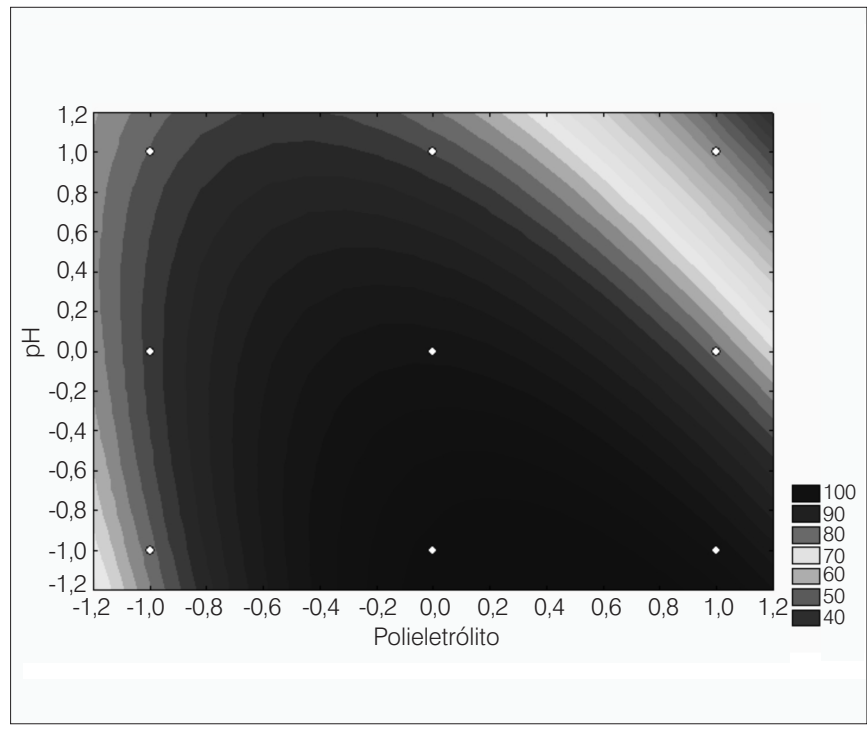

Figura 5 - Superfície de resposta para variável turbidez em função da variação de polieletrólito e pH para os ensaios 1 a 27.

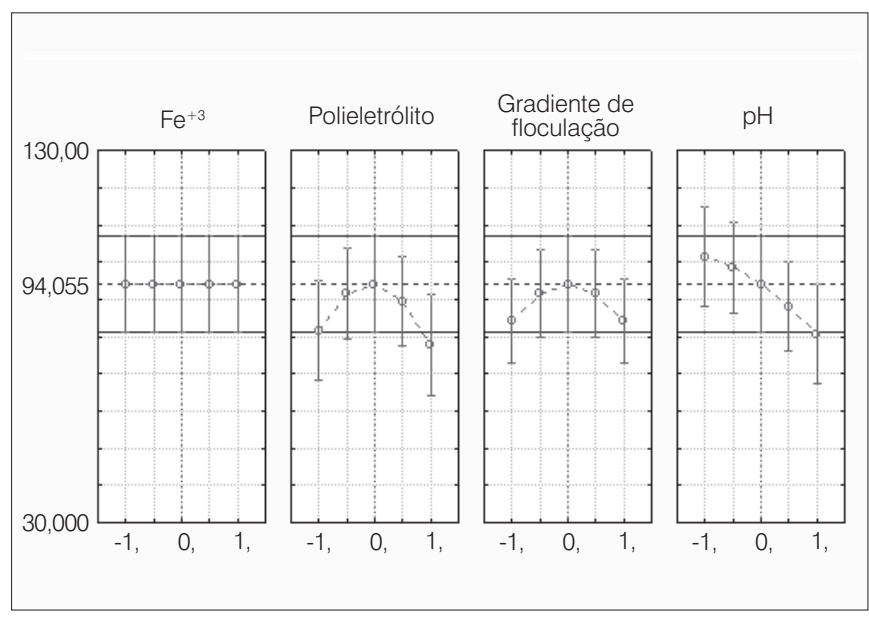

Figura 6 - Valores previstos para 0 modelo matemático da variável turbidez.

e DQO. Para tanto, fixou a dosagem de $400 \mathrm{mg} \mathrm{Fe}^{+3} \mathrm{~L}^{-1}$ combinado com pH 3,0 e tempo de sedimentação de 6 horas.

Embora as eficiências de tratamento sejam semelhantes às encontradas no artigo de Felici (2010), nota-se que os índices de remoção encontrados no presente trabalho foram alcançados com maior economia de coagulante, acidificante e tempo. Deste modo, avalia-se que a adição de polieletrólito ao tratamento do lixiviado por coagulação-floculação-sedimentação trouxe melhorias ao processo.

Com relação aos polieletrólitos, observa-se que os três tipos testados apresentaram bons índices de remoção com relação às variáveis analisadas. No entanto, com base nos valores previstos obtidos para os parâmetros investigados, verifica-se que o polímero com carga positiva conferiu maiores eficiências de remoção para as variáveis respostas escolhidas, estando de acordo com resultados descritos por Bila et al. (2005). 
Deste modo, com base nas análises estatísticas apresentadas, pode-se definir como as melhores combinações dos parâmetros analisados, a dosagem de $300 \mathrm{mg} \mathrm{Fe}^{+3} \mathrm{~L}^{-1}$ para coagulante, o pH 3,5 e o polieletrólito catiônico. Com relação ao gradiente de floculação, como não se verificou grande influência do mesmo sobre o processo, na faixa estudada, convencionou-se, por questões econômicas, a adoção de $20 \mathrm{~s}^{-1}$.

\section{Conclusões}

A adição de polieletrólito ao processo de tratamento físico-químico por coagulação-floculação-sedimentação se mostrou uma ótima alternativa, pois permitiu a diminuição das dosagens de coagulante (de 400 para $300 \mathrm{mg} \mathrm{Fe}^{+3} \mathrm{~L}^{-1}$ ) e acidificante (de $\mathrm{pH} \mathrm{3,0} \mathrm{para} \mathrm{3,5)}$ mantendo as eficiências de remoção e utilizando-se um tempo de sedimentação menor (de $6 \mathrm{~h}$ para $30 \mathrm{~min}$ ).
Através do uso das técnicas de planejamento experimental verifica-se que as variáveis mais significativas ao processo são a dosagem de coagulante, polieletrólito e $\mathrm{pH}$.

Em todos os modelos matemáticos obtidos também foram observadas fortes inter-relações entre as dosagens de polieletrólito e as variações do gradiente de floculação e do $\mathrm{pH}$ às dosagens de ferro. Como já era esperado, também foi determinada grande inter-relação entre a variável ferro e $\mathrm{pH}$.

Dentre as condições testadas para o lixiviado em estudo, verificou-se que o gradiente de floculação não apresenta grande influência sobre o processo, podendo ser utilizado o ponto de mínimo $\left(20 \mathrm{~s}^{-1}\right)$.

Dentre os polímeros testados e dosagens utilizadas, o de carga catiônica apresentou-se como o mais eficiente, alcançando remoções de aproximadamente $97,7 \%$ para cor verdadeira, $81 \%$ para DQO e 98\% para turbidez.

\section{Referências}

AMOKRANE, A.; COMEL, C.; VERON, J. (1997) Landfill leachates pretreatment by coagulation-flocculation. Water Research, v. 31, n. 11, p. 2775-82.

AMERICAN PUBLIC HEALTH ASSOCIATION; THE AMERICAN WATER WORKS ASSOCIATION; THE WATER ENVIRONMENT FEDERATION (APHA; AWWA; WEF). 2005 Standards methods for the examination of water and wastewater, $21^{\text {th }}$ ed. Washington D.C.: APHA; AWWA; WEF.

BILA, D.M. (2000) Aplicação de Processos Combinados no Tratamento do Chorume. Dissertação (Mestrado em Ciências) - Universidade Federal do Rio de Janeiro, Rio de Janeiro. 109 p.

BILA, D.M.; MONTALVÃO, F.; SILVA, A.C.; DEZOTTI, M. (2005) Ozonation of a landfill leachate: evaluation of toxicity removal and biodegradability improvement. Journal of Hazardous Materials, v. 117, n. 2-3, p. 235-42.

CATALDO, D.A.; HAROON, M.; SCHRADER, L.E.; YOUNGS, V.L. (1975) Rapid colorimetric determination of nitrate in plant tissue by nitration of salicylic acid. Communications in Soil Science and Plant Analysis, v. 6, p. 71-80.

FELICI, E.M. (2010) Coagulação-floculação-sedimentação como póstratamento de efluente de sistema biológico em batelada aplicado a lixiviado de aterro de resíduos sólidos urbanos. Dissertação (Mestrado em Engenharia de Edificações e Saneamento) - Centro de Tecnologia e Urbanismo, Universidade Estadual de Londrina. Londrina. $139 \mathrm{p}$

HOFFMAN, V. (2007) Estudo da floculação convencional versus Ballated Flocullation em efluentes oriundos do acabamento molhado de couros.
Monografia (Engenharia Química) - Escola de Engenharia, Universidade Federal do Rio Grande do Sul, Porto Alegre. 43 p.

KJELDSEN, P.; BARLAZ, M.A.; ROOKER, A.P.; BAUN, A.; LEDIN, A.; CHRISTENSEN, T. (2002) Present and long-term composition of MSW landfill leachate: a review. Environmental Science and Technology, v. 32, n. 4 , p. 297-336.

KULIKOWSKA, D; KLIMIUK, E. (2008) The effect of landfill age on municipal leachate composition. Bioresource Technology, v. 99, p. 5981-5.

KURNIAWAN, T.A.; LO, W.; CHAN, G.Y.S. (2006) Physico-chemical treatments for removal of recalcitrant contaminants from landfill leachate. Journal of Hazardous Materials, v. 129, n. 1-3, p. 80-100.

MARINGONDA JUNIOR, A. (2008) Remoção de nitrogênio de lixiviado de aterros de resíduos sólidos urbanos empregando sistema de lodos ativados, composto por reator anóxico e aeróbio em série. Dissertação (Mestrado em Engenharia de Edificações e Saneamento) - Centro de Tecnologia e Urbanismo, Universidade Estadual de Londrina. Londrina. 136 p.

MARAÑON, E.; CASTRILLÓN, L.; FERNÁNDEZ-NAVA, Y.; FERNÁNDEZMÉNDEZ, A.; FERNÁNDEZ-SÁNCHES, A. (2008) Coagulationflocculation as a pretreatment process at a landfill leachate nitrificationdenitrification plant. Journal of Hazardous Materials, v. 156, n. 1-3, p. $538-544$.

ROCHA, J.C.; ROSA, A.H. (2003) Substâncias húmicas aquáticas: interações com espécies metálicas. São Paulo: UNESP. 120 p.

ROEHRS, F. (2007) Tratamento físico-químico de lixiviado de Aterro sanitário por Filtração Direta Ascendente. Dissertação (Mestrado em 
Engenharia Ambiental) - Universidade Federal de Ssanta Catarina, Florianópolis.

SARASA, J.; LLABRÉS, T.; ORMAD, P.; MOSTEO, R.; OVELLEIRO, J.L. (2006) Characterization and photo-Fenton treatment of used tires leachate. Journal of Hazardous Materials, v. 136, n. 3, p. 874-81.

SILVA, A.C. (2002) Tratamento do percolado de aterro sanitário e avaliação da toxicidade do efluente bruto e tratado. Dissertação (Mestrado em Engenharia Civil) - Universidade Federal do Rio de Janeiro, Rio de Janeiro. $126 \mathrm{p}$.
TATSI, A.A.; ZOUBOULIS, A.I.; MATIS, K.A.; SAMARAS, P. (2003) Coagulation-flocculation pretreatment of sanitary landfill leachates. Chemosphere, v. 53, n. 7, p. 737-44.

WISZNIOWSKI, J., ROBERT, D., SURMACZ-GORSKA, J., MIKSCH, K., WEBER, J.V. (2006) Landfill leachate treatment methods: a review. Environmental Chemistry Letters, v. 4, n. 1, p. 51-61.

ZOUBOULIS, A.I.; CHAI, X-L.; KATSOYIANNIS, I. A. (2004) The application of bioflocculant for the removal of humic acids from stabilized landfill leachates. Journal of Environmental Management, v. 70, n. 1, p. 35-41. 